\title{
Can peace research be applied?
}

\author{
ANATOL RAPOPORT ${ }^{1}$ \\ Mental Health Research Institute, University of Michigan
}

For the purpose of this discussion, I shall distinguish between "pure" and "applied" research (or science) on the basis of what is expected from it by society or, more precisely, by the agencies that support it. The expectations are specified in the statements of aims when research institutes are established or when projects are financed. They are manifested in reports rendered to the supporting agencies. I shall call "pure" research that which fulfills the expectations by making some portion of the world better understood without necessarily bringing it under manipulative control. By "applied" research I shall understand that which makes possible an extension of control over some portion of the world.

Institutionalized science, that is, research organized into large enterprises with administrative structures, chains of authority, division of labor, budget accounting, etc., is all applied science. It has come into being in industrial societies where "progress" is identified with increasing manipulative control over the environment. Industrial societies support these large scientific enterprises and expect that their "product" will contribute to "progress." The most obvious successes of applied science have been translated into

\footnotetext{
${ }^{1}$ An Italian translation of this article is forthcoming in an anthology on problems of peace and war by Edizioni della Nuova Antologia (Rome). The English version is printed here by permission of the publishers in Rome.
}

technological advances. "Control of environment" thus acquired its conventional meaning: channeling forces of nature to do man's work (industrial technology); corraling energy for use against human enemies (military technology); shielding man from diseases (medical technology).

In the last two decades, the "behavioral sciences" became another sector of institutionalized science. The social expectations with regard to the behavioral sciences are reflected in the theme that usually underlies the arguments for social support of institutionalized behavioral science:

\footnotetext{
"Science has been phenomenally successful in providing solutions to age-old problems. It has made man master of his environment. It has prolonged life and has overcome many diseases. Now there is a widespread recognition that man's understanding of his environment has far outstripped his understanding of himself. As a result, man is helpless before a host of social ills, many of which spring from the very lag between man's ability to control nature and his ability to control himself. We need a science of man to solve the social problems that have arisen in the rapidly changing manmade environment."

Now, institutionalized research in the natural sciences was not established to cope with problems so formulated, such as: man is enslaved by physical toil; man is plagued by diseases, etc. It was only after the potentialities of the natural sciences for solving technical problems became apparent that natural science was institutionalized. Nevertheless, in spite of the fact that few, if any, of the so-
} 
called social problems have been formulated as problèmes bien posés, the behavioral sciences have been partially institutionalized in the sense that a measure of public support is given to organized projects in the behavioral sciences, increasingly recognized as a branch of the "scientific enterprise."

I believe this development can be attributed to two circumstances. First, there is a "halo effect." Science has been uniformly successful in "solving problems." Social ills are seen as "problems" and it seems sensible to direct the proven tools of scientific investigation toward the task of coming to grips with them. The fact that the social "problems," as usually stated, are not scientifically tractable problems is obscured by language. Second, the needs of business, of the military establishment, and of complex technology direct attention to certain aspects of human behavior. Accordingly, behavioral scientists have been enlisted in the service of business, of the military, and of technocracy. We now have, as branches of institutionalized behavioral science, industrial psychology, where the object of study is man as a component of a technical complex; market research, where man is studied as a consumer or as an object of persuasion through the mass media; and so on. Sociology is represented through its techniques in assessing mass moods and "public opinion"; anthropology has contributed to techniques of counter-insurgency, and so on. These "technical" branches of social science disciplines, concerned essentially with socalled human engineering, provide the principal leverage to the increasing institutionalization of the behavioral sciences. At the same time the lofty ideal of directing the scientific method toward the alleviation of social ills provides a stimulus to public support and, perhaps, serves the function of attracting concerned young people to the study of the social sciences. This is the "halo effect."

The prospects for an applied "science of peace" should be examined in this setting. The goal of peace research, as it is usually stated, is to discover conditions that facilitate or inhibit the establishment of world peace or, alternately, conditions that facilitate or inhibit wars. On this basis, suggestions have been made for making peace research a recipient of public or semi-public funds. The extent to which such support can be obtained depends, as in the case of the behavioral sciences, on two factors: the "halo effect" and prospects for technical accomplishments.

The "halo effect" derives from tacitly identifying "research" with the understanding of a phenomenon and gaining control over it. We have learned to control the forces of nature by understanding their "operations." We have learned to control or eradicate diseases by understanding their etiology. In the same way, it is believed, we should be able to eliminate large scale conflicts-such as wars-once we have understood the conditions that inhibit or facilitate them.

On closer reflection, however, it can be seen that understanding a phenomenon does not automatically confer the power of controlling it. For example, few phenomena are so well understood as the motions of heavenly bodies; yet it is unfortunately (or, perhaps, fortunately) not given to man to control them. However, since understanding is so frequently a prelude to control, research aimed at understanding can be justified on utilitarian grounds as preparing the way for eventual control. This is especially true when understanding and control are on the same "level," so to speak. For instance, a complete understanding of physiological aging, or of cancer, can be expected to be expressible in biophysical or biochemical terms. It is highly probable that control of these processes will also involve biophysical or biochemical intervention.

The situation is different if understanding and control are on different "levels." We 
understand the "cause" of the impending population explosion very well. It is a direct consequence of the drastic reduction in infant mortality, especially in countries with large birth rates. Moreover, we have the technical means of controlling births without recourse to sexual abstinence. What we cannot do at present is make these means available to the bulk of the world population and assure their use even if they are available. So, while the problem of birth control has been effectively solved on the physiological level, the solution of the population problem eludes us on the social level. We do not even know whether on that level the obstacles to the solution are primarily political, sociological, or psychological; that is, whether concerned efforts to solve the problem should be directed toward enlisting the help of highly placed political leaders, or of local social leaders; or whether it is more important to design techniques of birth control more acceptable to the people of the various cultures. Or it may be that the "solution" lies in an entirely different direction-for example, an increase of the global food supply, on the supposition that a wellfed population is freed from psychological compulsions to procreate at a maximum rate. However (and here is the main point), even if we knew "the answer," the problem would still remain unsolved unless institutions were created through which the solution could be implemented. For it is not enough to say what must be done. It is also necessary to say who should do it. And if the designated agency is powerless or unwilling or does not exist, the "solution" is not a solution. The problem is merely relegated to another level.

As another example, let us examine a social problem effectively solved, at least in the technically advanced countries, namely the control of certain epidemics. Typhoid is controlled by purifying water supplies; smallpox is controlled by vaccination. The medical problem of identifying the cause of typhoid was solved long ago. Thereafter the control of typhoid became an engineering problem, not a medical one. And the solution of this problem, in turn, depended on the cooperation of politicians (as is dramatized in Ibsen's play, The Enemy of the People). Mass vaccination involves mass indoctrination and appropriate institutions. Only the existence of such institutions permits us to push the solution to the end, so to speak. To avoid smallpox, a person should be vaccinated. This is saying what must be done. But who is to do it? We have the answer to that question: a nurse. But a nurse needs a place, a needle, vaccine. Who is to provide them? A public health agency. A public health agency needs authority to administer mass vaccinations. Who is to give it? The Department or Ministry of Health. And the department is itself a creation of the highest organs of government, which are also enlisted in inducing people to submit to vaccination.

All applied science implies an institutional structure. In each case of "problems solved by science," institutions have existed ready to receive the knowledge gained by the scientists in their investigations, institutions willing and able to translate that knowledge into techniques and empowered to apply the techniques. The fact that we spend our evenings in well-lit rooms rather than by candlelight we owe not only to Volta's discoveries. We owe it to the fact that the industrial age produced a social role for the inventor, eager to translate the discoveries of the physicists into utilitarian ideas; to the fact the rewards for successful inventions were so high that Edison was willing to spend years in trial-and-error search for a suitable filament for an electric bulb; that the utility magnates saw the commercial potentialities of the invention. My colleague in the Soviet Union can substitute, for the las link in that chain, Lenin's conviction that "socialism equals Soviet power plus electric power," and the consequent priorities given 
to electrification in that country's industrialization program. In short, institutional implementation is an indispensable phase in the utilitarian exploitation of institutionalized science.

The first question, then, that should occur to those who hope to link peace research to an applied science is the following: what institutions are available, or can be reasonably expected to be created, that can translate the findings of peace research into action directed toward the solution of the problems posed to it?

It is difficult to think of any. Recommendations for measures to be undertaken in the interests of promoting peace are not lacking. Some of them have been supported by careful analyses and sober estimates. Proposals have been made to establish a world government and to strengthen the peace-keeping agencies of the United Nations; plans for phased disarmament have been worked out and specifically designed to guarantee the security of the disarming nations. Further research may lead to a variety of additional proposals for war-preventing and peace-keeping measures. In short, there is no lack of knowledge about "what men could do" to insure peace. The question is how can such knowledge be used.

Note that in the case of scientific findings relevant to technology, to war-making, or to medicine, institutions exist wherein any scientific findings that promise advances are taken seriously. Here not only the question "What should be done?" but also the question "Who should do it?" can usually be answered immediately and explicitly. And if findings are sufficiently important and sufficiently promising, then, if no existing institutions can implement them, new institutions are created. In the case of at least some plausible findings of peace research, especially findings that relate the sources of war to some firmly entrenched institutions, questions related to the implementation of proposed solutions are bound to remain unanswered. Not only are the institutions required to implement such solutions nonexistent, but also prospects of creating them are nil, because decisionmakers on whom institutional changes depend and whose interests may be affected by them are receptive to only a very limited range of advice.

It may be argued that there is a fundamental difference between the findings of natural science and the findings of social science on which peace research would presumably draw. The former are consistently and remarkably reliable; the latter are not. This is true. However, it is also true that the existence of institutions and their readiness to translate "knowledge" into practice often has little relation to the reliability of this knowledge. For instance, the medical profession is much older than scientific medicine. Before the advent of scientific medicine, the healing art consisted of practices based on a mixture of crude experience and superstitions. The speculations of physicians on the genesis of disease were far from reliable knowledge. Yet these speculations were readily translated into practice by the medical profession. The efficacy of the healing art remained very low. Nevertheless, the fact that medicine existed as an institution made scientific advances eventually possible, because the institution provided the opportunity for theory and practice to interact (a necessary condition for any applied science), hence for a medical science to develop. Because there are no institutions where the theoretical findings of peace research can interact with practice (say, institutions empowered to practice "experimental foreign policy"), the prospects for developing an applied "science of peace" remain dim.

The idea of "experiments in foreign policy" may appear weird in view of the tremendous dangers attending a "wrong experiment." However, these dangers can be properly assessed only in comparison with the dangers inherent in the foreign policies presently conducted. It is not likely that present 
policy-makers would be inclined to make such comparisons.

One prospect of institutionalizing peace research, that is, of assuring it sources of public support and a utilization of its findings, does remain. This could be done if peace research were centered on questions that the policy-makers want answered and that, moreover, can be answered in ways that do not challenge the policy-makers' accustomed frameworks of thought.

One class of such questions relates to the dangers of a so-called accidental war. The spectre of accidental war has been raised by the nuclear balance of terror. Since a country can now be obliterated in a matter of minutes, and since it is taken for granted that an attack will be automatically retaliated, a "mistake" in the initiation or transmission of messages or orders (especially as the war machine becomes progressively more automated) can trigger a holocaust that no one intended. Such a prospect is not attractive to the decisionmakers of either of the two nuclear superpowers; consequently, technical solutions of this "problem" are welcomed. Solutions are envisaged essentially as safety margins against the malfunctioning of the war machines. The science involved in their design is technological and therefore no challenge to political habits of thought. Moreover, the solutions are not expected to confer any real or imagined political or military advantages on the "enemy," and so the political obstacles to their implementation are minimal. On grounds that the research involved in improving the "safety" of the weapons systems serves to alleviate the danger of war (in this case of "accidental war"), it could, supposedly, be called applied "peace research."

Another class of questions that interest the decision-makers of the superpowers, particularly of the United States, are those related to arms control. Because of the staggering costs of the present military establishments, and possibly for certain political reasons, negotiations on arms control and even disarmament have been going on primarily between the Soviet Union and the United States. By arms control the military experts usually understand ceilings on armaments at or above the present levels. Disarmament means any reduction of the present levels.

Related issues are those involving the testing of nuclear weapons. Testing in the atmosphere, it will be recalled, attracted much public attention because of the effects of radioactive fallout, particularly the contamination of milk with strontium 90 which gets into children's bones. Considerable public pressure developed in the United States for discontinuing the tests, and the issue became one of political concern to the government. Soviet leaders likewise considered a limitation on the development of nuclear weapons to be in their interest. After two years of negotiations it was possible for the US and the Soviet Union to effect an agreement to refrain from further tests of nuclear weapons in the atmosphere. What made the agreement possible was the fact that atmospheric testing is detectable anywhere on earth, which obviated the necessity of on-site inspections to prevent "cheating," such inspections being unacceptable to the Soviet Union. But, because on-site inspections could not be dispensed with in the case of underground tests, agreement on the suspension of these tests could not be reached. Here, then, is another purely technical problem, which, if solved, would permit another step in the direction of "arms control." For, if on-site inspections are actually the only obstacle to agreement with regard to suspending underground tests, then an improvement of seismographic techniques may remove the obstacle by making on-site inspections unnecessary.

Other problems related to arms control and disarmament involve the determination of limits on certain weapons (or possibly reductions of levels) which could not, in the opinion of the military experts, "jeopardize the secur- 
ity of the nation." Public Law 87-297, which established the United States Arms Control and Disarmament Agency, states this criterion explicitly: "Arms control and disarmament policy, being an important aspect of foreign policy, must be consistent with national security policy as a whole." Since "national security" of the superpowers is defined by those to whom it is entrusted, that is, essentially by military experts, it is they who are the final arbiters on what arms control and disarmament measures may be undertaken. In considering these questions, the experts must carry out certain estimates and calculations, mainly to determine what weapons may be limited or abandoned without reducing the indices in terms of which "national security" is measured (e.g., over-kill, etc.). The use of this expertise can also be subsumed under applied "peace research." Indeed, not only the US Arms Control and Disarmament Agency but also the RAND Corporation and similar organizations engaged primarily in weapons and strategic research have on occasions pointed out that they, too, are doing "peace research."

These purely technical achievements of "peace research" (if it can be so called) just about exhaust the range of scientific findings applied in the interest of preventing immediate war. Needless to say, the scope of these achievements is severely limited and their relevance to the central problem, the longrange prevention of war and the advancement of world peace, is questionable.

The situation parallels that in the institutionalized behavioral sciences. The actual applications of findings in the behavioral sciences are limited to techniques that can be used by existing institutions: business, military, bureaucratic, etc. The grandiose aims of a "science of man" remain unfulfilled. It is not that social scientists do not exert efforts to disclose and understand the roots of gross social evils. Many do, and they freely publish their findings. However, as has been said, a science can become an applied science only in the process of interacting theory and practice. If there are no institutions to provide the practice, there will be no such interactions and the theories will remain suspended in the intellectual sphere, to be discussed for a while and then forgotten. New theories will replace them to suffer the same fate. Possibly, among all the theories, some could provide the key to the solution of important social problems. But we shall never know, if the implementation of the solutions suggested by the theories involves a radical overhauling of our institutional structure.

Let us turn to peace research that does not depend on support by the big research establishments of the superpowers. There are a number of small centers supported by private funds, or nestling in inconspicuous niches of universities. Examples are the Canadian Peace Research Institute, the Center for Research on Conflict Resolution at the University of Michigan, the Citizen's Committee on Nuclear Information in St. Louis, Missouri, the Conflict Research Center in Copenhagen, and the Oslo Peace Research Institute. The Stockholm Peace Research Institute is institutionalized in the sense of being governmentsupported; but since Sweden is a neutral country, it should be counted with the "independent" research centers. The product of these institutions is publications. These range widely in subject matter from public opinion surveys to historical essays, from mathematical models of arms races to assessments of ethnocentrism, from military economics to the theory of games. Much of this work could easily be subsumed under academic social science. It stems from the same sort of motivation, and is pursued by the same methods. One finds review articles, reports of experiments (for example, in simulated conflict), methodological discussions, collections of data, data processsed into "indices," data supporting or refuting hypotheses, etc.

Needless to say, the financial situation of 
all these centers is chronically precarious. Procurement of funds is invariably associated with a statement of aims, and it is usually most difficult to justify support for the purpose of advancing knowledge for knowledge's sake. This can be done in the case of longestablished disciplines like astronomy or philosophy. "Peace research," however, is not an established discipline-not even a discipline, for that matter. It is distinctly "interdisciplinary." This term still retains some of its magic (although much of it has worn thin), but the avowed aims of "interdisciplinary" research efforts have always been problemoriented. In fact, the principal rationale for interdisciplinary endeavor is that of counteracting the fractionation of science by illuminating "problems" from several directions. At any rate, peace research is not in a position to ignore the applicability of its product to the "problem" of war.

What impact can we expect from the products of the independent peace research centers? One hope is that the very activity of the centers will serve to keep "the problem" in the public eye or at least will claim the attention of the academic community, especially among the young. The centers can provide at least a temporary niche for young people eager to do "relevant" research, and so prepare the cadres for future constructive developments in social science. Another hope is that the centers can make an impact by disseminating information to the general public. This function of peace research was adopted, for example, by the Citizen's Committee on $\mathrm{Nu}$ clear Information in St. Louis. They publicized facts about the effects of atmospheric testing of nuclear weapons that had been suppressed or semi-suppressed by government agencies. Later the same committee published analyses of the effectiveness (or the lack of it) of fallout shelters and brought the issue of "civil defense" into the limelight of vigorous public debate. To take another example, the Stockholm Peace Research Institute has been conducting studies on the effects of bacteriological warfare and on world armament trade. The implicit (sometimes explicit) assumption in these enterprises is that the dissemination of information, to which the public might otherwise not have access, helps to educate the public in matters pertaining to the problem of war, and that an informed citizenry may be better equipped to cope with measures that lead to war.

Researchers involved in this work emphasize the importance of keeping the informative and the persuasive aspects of the dissemination of information strictly separate. The authority of the scientist, they argue, resides in his freedom from bias. In fact, the primary, perhaps the sole responsibility of the scientist, the argument goes, is the acquisition and the dissemination of knowledge; and it is not his function as a scientist to persuade. He may, of course, do this as a citizen, but must always be careful to separate the two roles. This insistence on the "neutrality of science" stems from a conviction that only if the total "objectivity" of science is preserved can science retain its authority in human affairs.

One might say in passing that the "objectivity of science" does not extend to the choice of research directions. Decisions about what is relevant or important knowledge depends as much on the convictions and commitments of the scientist as on his dispassionate examination of facts and carefully reasoned conclusions. Be that as it may, one will readily grant that the "authority of science" derives from its freedom from bias once the direction of research and the method of investigation have been chosen. However, in discussing the possible impact of peace research on policies concerned with war and peace, the main question is not whether science enjoys authority but whether the authority of science makes any difference in the policies. The policymakers do not need to dispute the findings on the effects of nuclear fallout, on the effects of bacteriological warfare, or on the extent of 
world armament trade. Neither do they need or are they likely to take these findings into account in designing and pursuing their policies. The only relevant effect of the dissemination of information is its possible influence on the population as a whole. If the information made available does in fact reach the public, or politically important sectors of it, and if the publics so informed are moved to action, and if this action does have political results, then we can say that "peace research" has made an impact by way of producing relevant knowledge and disseminating it. So far, such impacts have been spotty and, in general, they are difficult to assess. There may be, however, a cumulative effect that will eventually be manifested in stronger and more consistent action.

But it should be clear that, in fulfilling its enlightening function, peace research does not thereby contribute to an "applied science." It would, only if the knowledge produced by it were used to organize and guide (not merely motivate) actions directed toward the prevention of war or the establishment of peace. As has been said, governments are not likely (except in certain limited areas) to be guided by knowledge produced by peace research; while publics, although they may be aroused to resist policies that aggravate the danger of war, or to advocate policies that advance peace, also need some knowledge of ways to organize and direct effective action. Such knowledge is not at present generated by peace research.

Criminology provides an analogous example. On the one hand, criminology is an academic discipline concerned with the genesis, the epidemiology, and the psychology of crime. This is pure, not applied, science so long as its findings are not used as a concrete guide to action with regard to crime (which by and large they are not). There is also another kind of criminology: the science of crime detection with its laboratories, records, methods of information retrieval, etc. This criminol- ogy is, of course, an applied science. Academic criminology as a pure science may provide valuable insights into the roots of crime; but as long as it remains a pure science, that is, as long as it is not coupled with knowledge of how to translate its insights into concrete actions-knowledge of who is to do what, when, where, and how-criminological research can make no impact on crime.

The police criminologist, although he has at his disposal techniques for identifying and apprehending individual criminals, is likewise powerless to deal with crime as a social phenomenon. There is no necessary connection between the efficiency of detection techniques and the incidence of crime. Is there a way of combining the relevance of the academic criminologist's insights with the effectiveness of the police criminologist's techniques? There may be. There are problems of intermediate scope, more concrete than the academic criminologist's but reaching deeper into the social structure than the policeman's problems.

Consider the task of eradicating crime, not in the abstract, but in one of its concrete yet broad social manifestations-for example, organized crime in the United States. The task would require a considerable amount of sophisticated research. The structure of criminal syndicates would have to be understood in all its intricacy; also the interconnections between the syndicates and the political machines, and between these and business interests.

If the task is kept constantly in mind, the thrust of the research will have to be directed toward discovering the nexus of these interconnections, their vulnerable links, etc. It may turn out that research of this sort would require certain interventions: for example, attempts to disrupt the operations of the criminal syndicate in order to see how it responds to threat. Clearly, then, the research effort would have to be coupled with social action. It may involve the enlistment of people out- 
side the research organization proper, people with practical experience in such matters. It is also clear that all these activities could not be kept on the level of "moral neutrality," which is typically demanded of the scientist. The people involved may be required to take considerable risks and so would have to be strongly committed.

There would thus be a price to pay. The traditional separation of the "discovery of truth" and of action on the basis of commitments would have to be abandoned, because the very nature of the research would demand that the two be combined.

I believe the situation in peace research is similar to that in criminology. On the one hand it is possible to develop broad theories of war and peace, of conflict and conflict resolution. These may give us valuable insights into the genesis of wars and the conditions of peace. So long as these insights are not coupled with specific knowledge of how to prevent some conditions or bring about others, the insights will be of little or no immediate help in preventing war or promoting peace. Projects for a world government, for restructuring the United Nations, for disarmament, or for reorganizing world economics can make no impact unless the research that inspired them also produces knowledge of how actually to implement these projects.

On the other hand, certain specific applicable techniques of conflict resolution or tension-reduction may emerge from peace research. The "safeguards" put on automated war technology may reduce the itch on the trigger fingers. Other techniques may be useful in specific instances-for example, in communal strife, or in wars between small nations that can be arrested by "higher authority"; in short, in those cases where institutions empowered to control the conflicts already exist (or can be created) and where new techniques put at their disposal can make them more effective.
As in the case of the two criminologies, we have, on one level, broad "pure" peace research that remains impotent in dealing with war as an actual occurrence, and, on another, a set of techniques that may alleviate the symptoms without reaching to the roots of the problem.

We need an intermediate research task, one directed at a "large" problem, such as the chronic danger of a devastating war between nuclear powers, and yet at the same time a concrete one, centered on the operation of actual war-making institutions. In choosing such a task, the eclectic attitude toward the "causes of war" would have to be abandoned. A specific hypothesis would have to be chosen; for example, that war between great powers, far from being an aberration, is a normal activity of military establishments, in the same way that organized crime is a normal activity of criminal syndicates. On a priori grounds, such a hypothesis is no more and no less credible than other hypotheses or philosophic conceptions of war, such as "War is a manifestation of man's aggressive urges," or "War is a malfunctioning of the international system instigated by a disturbance of the balance of power," or "War is a political instrument." Note that all these conceptions of war are academically respectable, while "War is an analogue of organized crime" apparently is not. The onus of the latter derives from two sources. One, already mentioned, is that, if the conception is adopted as a hypothesis, its test involves action of the sort that violates the dictum of separating the scientist's responsibilities from his political commitment. Another source is that the hypothesis is easily confused with a conspiracy theory of the sort advanced by cranks.

The latter objection is not warranted. The operations of "real" criminal syndicates do indeed involve conspiracies, because they circumvent statute laws. The operations of military establishments do not. Th\% investigation of the institutional strur.ure of military 
establishments, of their sources of power, and of their interconnections with the total institutional structures of war-waging states would be directed not toward exposing a conspiracy but toward revealing the "normal" functioning of an organic system. In this sense, the underlying philosophic orientation would be rather similar to the one embodied in the conception of war as a disease. Here the ambiguity of the term "normal" would be revealed. A parasite within a host functions "normally" as a parasite. But the host is sick. In this conception, war would appear not as a disease that now and then "befalls" the organism but as one that resides within the organism as a malignancy with its characteristic hypertrophy and parasitism.

It remains true, however, that the conception of war as an analogue to organized crime, unlike other academically more respectable conceptions, would lead peace research into areas of activity traditionally avoided by scholars and scientists practicing their calling.

In particular, as Gabriel Kolko has pointed out (The Nation, October 9, 1967), one of the vulnerable spots of the United States military establishment is its extensive dependence on universities, where some of the most important war research is carried out. Peace researchers in universities are thus in a favor- able position to gain and disseminate knowledge about the extent and the nature of war research coupled with knowledge, gained from experience in action on campuses, of how the military machine can be attacked where it is vulnerable.

Further, like the investigation of the operations of criminal syndicates and of their interconnections with the entire institutional structure, the investigation of the war machine and of its connections would involve social or political action, and would probably make necessary the enlistment of people outside the research community proper. The product of such research would be not only an understanding of how the war machine operates, and how the war machines of rival great powers support each other, but also, perhaps, some ideas of how to prevent the global war machine from fulfilling its "normal" function, that function being fatal to humanity.

Perhaps from this fusion of knowledgeseeking and social action, an "applied science of peace" will emerge, just as in another age natural science was born when philosophers overcame their reluctance to handle things and moved into laboratories, that is, workshops where craftsmen and artists were already busy. 